\title{
Placenta Of Late Onset Preeclampsia Without Fetal Growth Restriction : Is It Different From The Normal?
}

\author{
Original \\ Article \\ Alaa Wageh ${ }^{1}$ Reham Mohamed Nagib ${ }^{2}$, Mohamed Ibrahim Eid ${ }^{3}$ \\ ${ }^{1,3}$ Department of Obstetrics and Gynecology, ${ }^{2}$ Department of Pathology, Faculty of Medicine, \\ Mansoura University, Egypt
}

\begin{abstract}
Background: Preeclampsia (PE) is one of the most common pregnancy complications affecting approximately $5-7 \%$ of pregnant women worldwide. Pathogenesis of PE is still mysterious. Literature studies reported differences between early and late onset PE. Also, whether placenta of late-onset PE without fetal growth restriction (FGR) is different from normal one needs further declaration.

Objective: This study aims at evaluating the placental microvessel density (MVD), apoptosis and endoglin (CD105) expression in late-onset PE without FGR.

Patients and Methods: Placentae of $15 \mathrm{PE}$ and 15 matched control ones were evaluated grossly, microscopically and by immunohistochemistry for caspase-3, CD 34 and CD105.

Results: Placentas in PE group showed a statistically significant difference as regard size, syncytial knots, perivillous fibrin deposition, villous infarction increased apoptosis, and endoglin (CD105) expression. However, the percentage of terminal villi and microvessel density (MVD) were comparable in both groups.

Conclusion: Placenta from late onset PE without FGR is still different from the normal placenta whatever time onset of PE pathogenesis may be similar. Absence of changes in MVD may explain good fetal outcome.
\end{abstract}

Key Words: Apoptosis, caspase-3, CD 34, CD105, pre-eclampsia

Received: 14 September 2018, Accepted: 17 October 2018

Corresponding Author: Alaa Wageh, MSc., Department of Obstetrics and Gynecology, Faculty of Medicine, Mansoura University, Egypt.

ISSN: 2090-7265, May 2019, Vol.9, No. 2

\section{INTRODUCTION}

Being one of the most common pregnancy complications, preeclampsia (PE) is a major cause of fetal and maternal mortality. Approximately $4-7 \%$ of pregnant women worldwide are affected ${ }^{[1]}$.

It is diagnosed by the presence of hypertension and proteinuria after 20 weeks of gestational age in a previously normotensive one. There are endothelial dysfunction and inflammatory conditions in multiple $\operatorname{organs}^{[2]}$.

Early-onset (placental PE) is associated with abnormal placental perfusion, low birth weight neonates and poor maternal outcomes. On the other hand, lateonset (maternal) PE occurs with better fetal outcome ${ }^{[3]}$.

Despite being well characterized clinically, pathogenesis of PE is still mysterious. Many theories have been proposed. It has been suggested that PE is characterized by defective cytotrophoblastic proliferation with increased apoptosis and defective cell fusion with subsequent diminished syncytial differentiation. This may lead to defective trophoblast invasion with insufficient placentation ${ }^{[4]}$.

Consequently, there is placental hypoxia that results in oxidative stress, production of debris and cytokines and a local inflammatory reaction. Moreover, increased apoptosis of the trophoblastic cells has been reported as an important component of PE pathogenesis which can result in deprivation of placental vasculature from angiogenic factors and release of antiangiogenic substances.

Such antiangiogenic substances (serum CD105) and inflammatory cytokines released into the maternal circulation can lead to systemic inflammatory response and endothelial dysfunction ${ }^{[5,6]}$.

Many studies have been done worldwide to unravel the mysteries of the placenta and to add evidence to the existing clinicopathological correlation studies. Whether these alterations considering apoptosis of the trophoblastic cells with the subsequent reduction 
in angiogenic factors will affect the fetal vascular development or not, this needs further declaration.

\section{AIM OF THE WORK}

This study aims at evaluating the placental apoptosis, CD105 expression and microvessel density (MVD) (fetal vasculature) in late-onset PE without fetal growth restriction (FGR).

\section{PATIENTS AND METHODS}

The present study is an observational case-control study that included placentas from 15 cases of PE compared with 15 other normal matched cases.

After elective cesarean section at Obstetrics and Gynecology Department at Mansoura University Hospitals, placentas for cases and control were sent to the Pathology Department. This study was carried out during the period between January 2017 and June 2017.

Pregnancy duration was calculated from the last normal menstrual period and ultrasound. PE was diagnosed when blood pressure was elevated more than $140 / 90 \mathrm{mmHg}$ together with proteinuria of $300 \mathrm{mg} / 24$ hours after 20 weeks of gestational age. Those women had no previous history of hypertension ${ }^{[2]}$.

Inclusion criteria were placentas of late-onset PE when manifestations appeared after the $34^{\text {th }}$ week of gestation and these patients did not have fetal growth restriction ${ }^{[2]}$.

Those patients who were in labor or had premature rupture of membranes or had preexisting medical conditions such as diabetes, chronic hypertension and renal disorder were excluded.

For the control group, 15 placentas were collected from normotensive pregnant women who were also delivered by cesarean section.

The Ethics Committee of Mansoura Faculty of Medicine approved this work.

Immediately after delivery, placentas were placed in $10 \%$ buffered formalin and left over night for fixation in the pathology laboratory.

Placentas were examined grossly mainly for their weight, shape, presence of thrombosed vessels and hemorrhage or calcifications. We used a cut off weight of $500 \mathrm{gm}$, below which is considered small and above or equal is considered average.

Sections were taken, processed and stained with routine H\&E. Stains H\&E sections were examined microscopically for features of placental hypoxic injury including the percentage of

-Syncytial knots

-Fibrin deposits in the intervillous space

-Villous infarction

-Terminal villi in relation to the whole villi

Syncytial knots were recognized when five or more nuclei of syncytiotrophoblast projecting from the villous surface $^{[7]}$.

Terminal villi, are smaller with less stroma, a discontinuous cytotrophoblast layer and contain 4-6 fetal capillaries per cross section. The fetal capillaries of the villous core oppose against thin attenuated syncytiotrophoblasts forming vasculo-syncytial membranes.

Increased perivillous fibrin deposits were considered when more than one-quarter of the villi were involved ${ }^{[7]}$

Additional sections were cut at $4 \mathrm{um}$ thickness and immunostained with antibodies for CD34, caspase 3 and (CD105) endoglin. After deparaffinization and rehydration, antigen retrieval was done in a pressure cooker until boiling (20 min) after placing the sections in EDTA (for both CD34 and CD105). Then, sections were incubated with the primary antibody for 1 hour at room temperature. The primary antibody for CD 34 was a mouse monoclonal antibody (Dako, IS 632) as well as for CD105 (Thermo, 1290P0), while for caspase it is rabbit polyclonal antibody (Neo Markers Fremont CA, RB-1197-P0). This was followed by application of secondary antibody, DAB, counterstaining then dehydration and mounting.

\section{Interpretation of IHC:}

\section{For assessment of MVD:}

Number of capillaries in placental villi in 3 microscopic fields for each case was counted using image analysis software (VT test) and the mean was calculated.

\section{For assessment of apoptosis:}

Sections immunostained with caspase 3 were evaluated as regard intensity and percentage of positive trophoblastic cells then $\mathrm{H}$ score was calculated. Cytoplasmic reaction is considered positive.

\section{For assessment of endoglin (CD105):}

Membranous reaction is considered positive. Intensity and percentage of positive cells were recorded in the form of $\mathrm{H}$ score. 


\section{STATISTICAL ANALYSIS}

Data were analyzed by the use of IBM SPSS software package version 20.0. Qualitative data were described using percent and number. Quantitative ones were described using median (maximum and minimum) for non-parametric data and mean, standard deviation for parametric data after testing normality using KolmogrovSmirnov test. Significance was judged at the 5\% level.

\section{The used tests were:}

1 - Chi-square test and Monte Carlo test to compare between different groups. Monte Carlo test was used as correction for Chi-Square when more than $20 \%$ of cells have count less than 5 for categorical variables.

2- Student t-test was used for parametric quantitative variables to compare between two studied groups.

3 - Mann Whitney test was used for non-parametric quantitative variables to compare between two studied groups.

\section{RESULTS}

Placentas for 15 cases of PE were compared to those of 15 age matched control cases. Age of cases and duration of pregnancy in both groups was illustrated in Table 1.

On gross examination 6 out of 15 placentas in PE group were smaller in weight compared to control ones and the difference was statistically significant. Grossly detected thrombosis was evident in only one case of PE as well as calcification.

The percentage of villi containing syncytial knots was greater in PE than in the control group with a statistically significant difference. The percentages perivillous fibrin deposition was significantly increased in PE compared with control.

Similarly, the percentage of villous infarction was more in PE than control. The difference was statistically significant.

However, there was no difference between both groups regarding the percentage of terminal villi (Table 1).

No statistically significant difference has been recorded between both groups considering MVD (Table 1).

There has been increased apoptosis of both cyto and syncytiotrophoblastic cells as evidenced by moderate to strong cytoplasmic staining for caspase 3 that is seen in $70 \%$ of villi. On the other hand, immunostaining for caspase 3 in normal placentas revealed moderate to weak staining reaction. The difference in $\mathrm{H}$ score between cases and control was statistically significant $(P<0.001)$ (Figure 1).

We found a statistically significant difference between both groups as regards $\mathrm{H}$ score $(P<0.001)$ being more in PE (Figure 2).

Table 1: Comparison between cases and control

\begin{tabular}{|c|c|c|c|}
\hline Parameters & $\begin{array}{l}\text { Cases } \\
\mathrm{N}=15\end{array}$ & $\begin{array}{l}\text { Control } \\
\mathrm{N}=15\end{array}$ & Test of significance \\
\hline $\begin{array}{l}\text { Age } \\
\text { Mean } \pm \text { SD }\end{array}$ & $28.0 \pm 5.2$ & $29.6 \pm 4.9$ & $\begin{array}{l}\mathrm{t}=0.89 \\
\mathrm{P}=0.38\end{array}$ \\
\hline $\begin{array}{l}\text { Pregnancy duration } \\
\text { Mean } \pm \text { SD }\end{array}$ & $36.3 \pm 0.9$ & $36.4 \pm 0.8$ & $\begin{array}{l}\mathrm{t}=0.2 \\
\mathrm{P}=0.8\end{array}$ \\
\hline $\begin{array}{l}\text { weight n (\%) } \\
\text { - Small } \\
\text { - Average }\end{array}$ & $\begin{array}{l}6(40.0) \\
9(60.0)\end{array}$ & $\begin{array}{l}0(0.0) \\
15(100.0)\end{array}$ & $\begin{array}{l}\chi 2=7.35 \\
P=0.006^{* *}\end{array}$ \\
\hline $\begin{array}{l}\text { Syncytial knots } \\
\text { Mean } \pm \text { SD }\end{array}$ & $73.3 \pm 10.5$ & $16.67 \pm 5.56$ & $\begin{array}{l}\mathrm{t}=18.5 \\
P<0.001 * *\end{array}$ \\
\hline $\begin{array}{l}\text { Perivillous fibrin } \\
\text { Median (Min-Max) }\end{array}$ & $10.0(10.0-20.0)$ & $3.0(2.0-10.0)$ & $\begin{array}{l}\mathrm{Z}=4.3 \\
P<0.001 * *\end{array}$ \\
\hline $\begin{array}{l}\text { Villous infarction } \\
\text { Mean } \pm \text { SD }\end{array}$ & $14.33 \pm 3.7$ & $4.33 \pm 1.2$ & $\begin{array}{l}\mathrm{t}=4.5 \\
P<0.001 * *\end{array}$ \\
\hline $\begin{array}{l}\text { Terminal villi } \\
\text { Mean } \pm \text { SD }\end{array}$ & $79.67 \pm 6.67$ & $77.3 \pm 8.8$ & $\begin{array}{l}\mathrm{t}=0.82 \\
\mathrm{P}=0.42\end{array}$ \\
\hline
\end{tabular}




\begin{tabular}{|c|c|c|c|}
\hline $\begin{array}{l}\text { CD34 } \\
\text { Median (Min-Max) }\end{array}$ & $\begin{array}{l}272.0 \\
(230.0-494.0)\end{array}$ & $\begin{array}{l}260.0 \\
(170.0-477.0)\end{array}$ & $\begin{array}{l}Z=0.29 \\
P=0.77\end{array}$ \\
\hline $\begin{array}{ll}\text { Caspase strength n }( \\
\bullet & \text { Negative } \\
\bullet & \text { Weak } \\
\bullet & \text { Moderate } \\
\text { - } & \text { Strong }\end{array}$ & $\begin{array}{l}0(0.0) \\
0(0.0) \\
6(40.0) \\
9(60.0)\end{array}$ & $\begin{array}{l}5(33.3) \\
6(40.0) \\
4(26.7) \\
0(0.0)\end{array}$ & $\begin{array}{l}\mathrm{MC} \\
P<0.001 * *\end{array}$ \\
\hline $\begin{array}{l}\text { Caspase Percentage } \\
\text { Median (Min-Max) }\end{array}$ & $\begin{array}{l}70.0 \\
(50.0-90.0)\end{array}$ & $\begin{array}{l}30.0 \\
(0.0-90.0)\end{array}$ & $\begin{array}{l}\mathrm{Z}=3.4 \\
P=0.001 * *\end{array}$ \\
\hline $\begin{array}{ll}\text { CD105 strength n }(\% \\
\bullet & \text { Negative } \\
\bullet & \text { Weak } \\
\bullet & \text { Moderate } \\
\text { - } & \text { Strong }\end{array}$ & $\begin{array}{l}0(0.0) \\
0(0.0) \\
4(26.7) \\
11(73.3)\end{array}$ & $\begin{array}{l}9(60.0) \\
6(40.0) \\
0(0.0) \\
0(0.0)\end{array}$ & $\begin{array}{l}\mathrm{MC} \\
P<0.001 * *\end{array}$ \\
\hline $\begin{array}{l}\text { CD } 105 \text { Percentage } \\
\text { Median (Min-Max) }\end{array}$ & $\begin{array}{l}80.0 \\
(60.0-100.0)\end{array}$ & $\begin{array}{l}10.0 \\
(0.0-20.0)\end{array}$ & $\begin{array}{l}Z=4.35 \\
P<0.001 * *\end{array}$ \\
\hline
\end{tabular}

Z: Mann Whitney U test $\quad \chi 2=$ Chi-Square test $\mathrm{MC}$ : Monte Carlo test

t: Student t test P:Probability ** high statistically significant if $p<0.01$

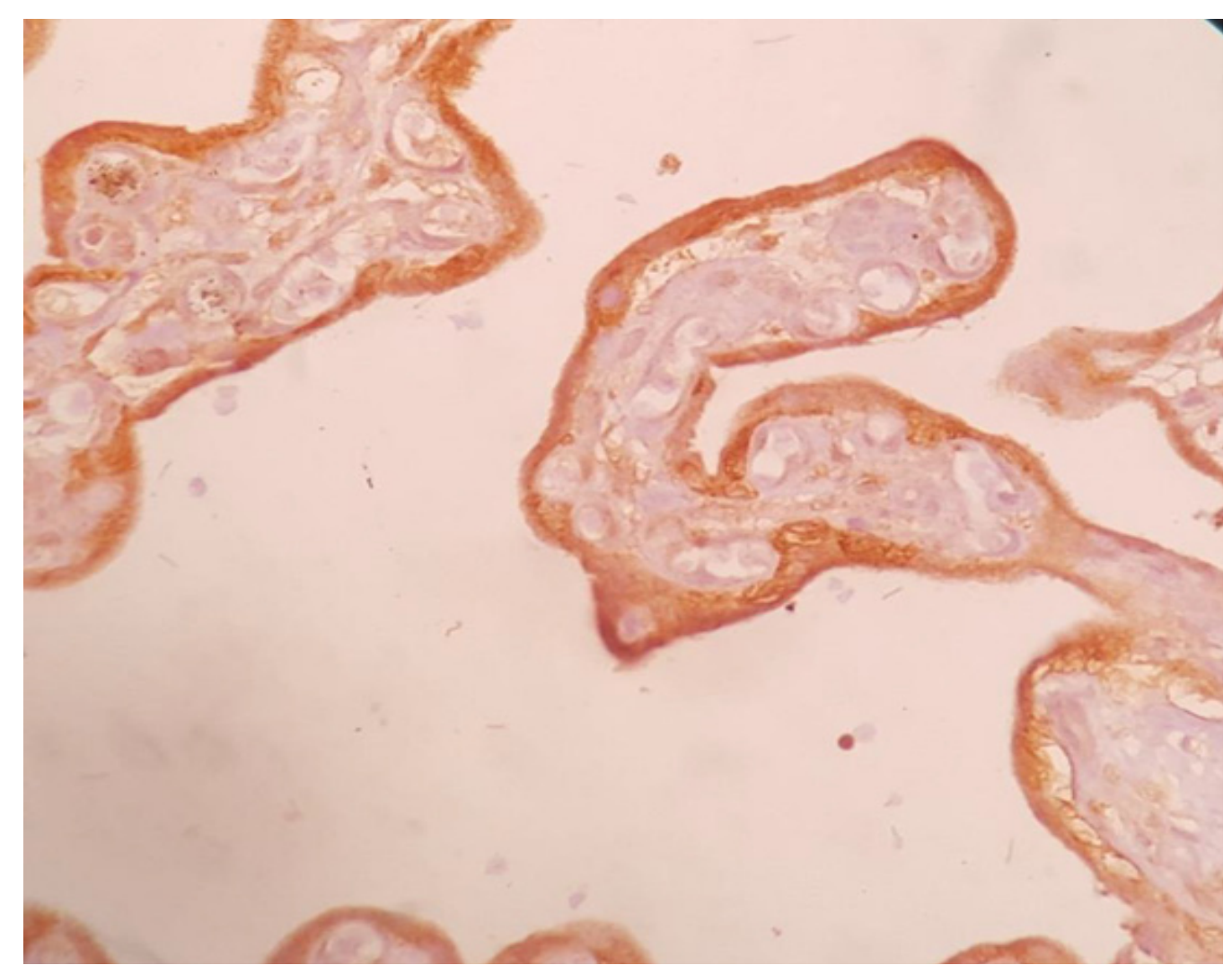

Fig 1: Section from placenta of preeclampsia showing syncytial knots (arrows) as well as perivillous fibrin (stars) .

(H.\&E. x100) 


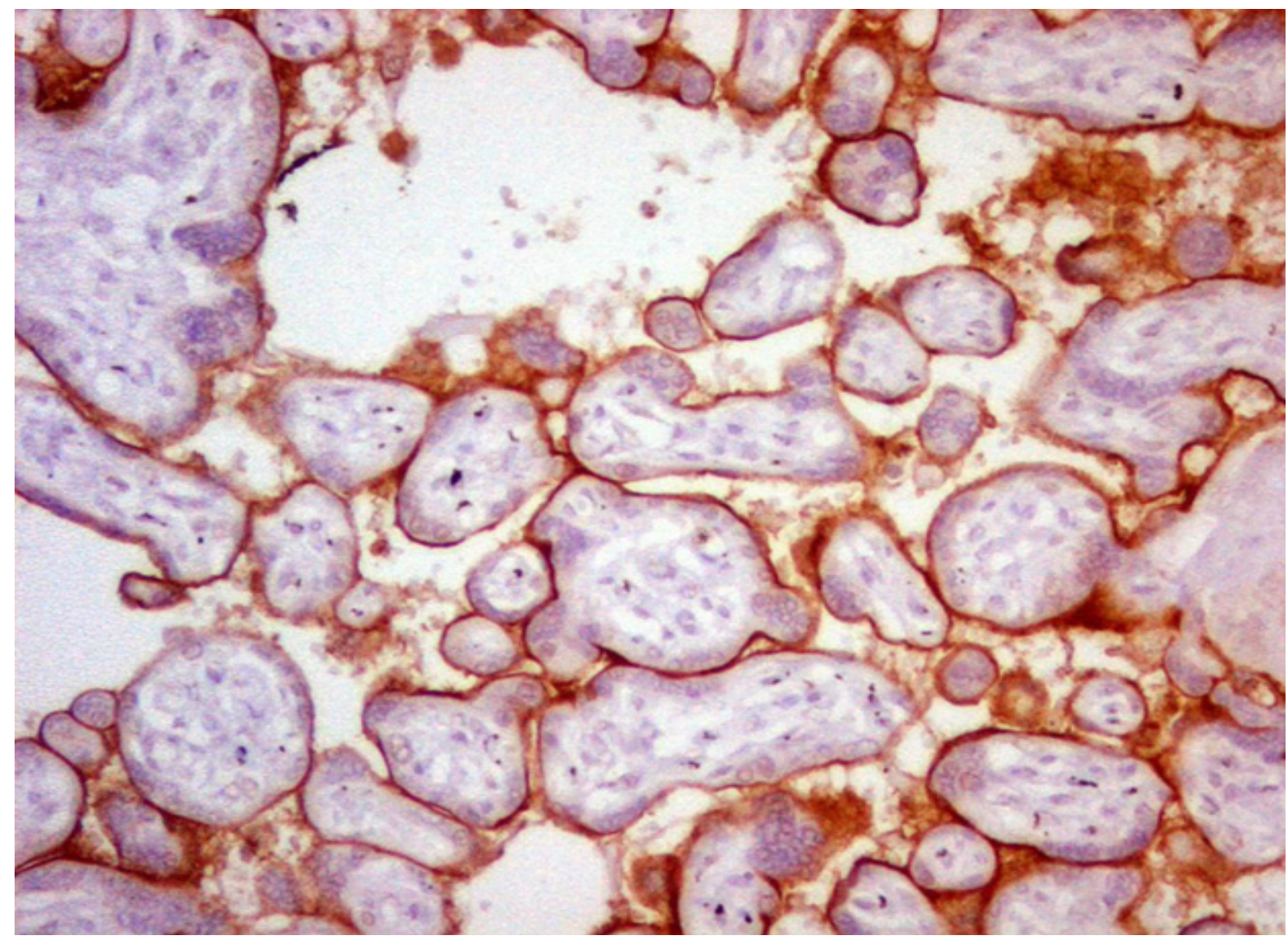

Fig 2: Strong cytoplasmic staining for caspase in preeclampsia

(IHC x400)

\section{DISCUSSION}

$\mathrm{PE}$ is a multisystem pregnancy related disorder with known maternal and fetal complications. Despite being well characterized clinically its mechanisms are still an enigma. However, it became well known that placental ischemia is the core of pathophysiology. Molecular defects in cytotrophoblasts have been suggested to be the underlying cause. These results increased trophoblastic apoptosis with subsequent defective trophoblastic invasion into spiral arteries decreased angiogenic and increased antiangiogenic factors.

We have gone through the study trying to answer a question; Does placenta of late onset PE without FGR differ from the normal one?

Yes, we have found differences concerning placental size, histomorphology as well as immunohistochemical findings. However, MVD was nearly similar.

There has been a statistically significant difference in weight being smaller in PE. This was in concordance to Predoi et al. (2015) Sankar et al., (2013) and Higgins et al., (2015) $)^{[1,8,9]}$.
As regard histopathological findings, the presence of syncytial knots, villous infarction and perivillous fibrin showed a statistically significant difference between PE and control group. On the other hand, there was no statistically significant difference considering terminal villi. This may be because the cases in the current study were all late-onset PE without FGR who delivered at term where normally placenta is expected to show this feature.

Similar to our results, Sankar et al. (2012) and Ptacek et al., (2016) reported increased syncytial knots in PE placentas with statistically significant difference ${ }^{[10,11]}$. Weel et al., (2016) and Kovo et al., (2012) reported increased prevalence of syncytial knots in PE placentas but with a significant difference between early and late onset PE than between late onset one and control group ${ }^{[2,7]}$.

Syncytial knots are reported as a form of trophoblastic hyperplasia as result of hypoxia ${ }^{[7]}$.

Considering villous infarction, our results were comparable to Vinnars et al., (2011) who reported that the amount of infarction significantly increased with the severity of PE rather than gestational 
age with a significant difference between $\mathrm{PE}$ and normotensive pregnancies $^{[12]}$. On the other hand, Weel et al., (2016) and van der Merwe et al., (2010) stated that late-onset PE and normal term placentas have fewer differences ${ }^{[3,7]}$. The placental infarcts may be due to occlusion of spiral arteries by thrombus, strangulation of the placental villi due to increased perivillous fibrin deposition and/or impairment of the fetal circulation due to fetal thrombotic vasculopathy ${ }^{[1]}$.

As regard perivillous fibrin deposits, Stark et al., (2014) reported results similar to ours ${ }^{[13]}$. Increased perivillous fibrin deposition can be due to increased activity of plasminogen activator inhibitor type 1. Some of the PE related complications may be explained by defective exchange of nutrients and gas at fetal maternal interface due to excessive deposition of fibrin ${ }^{[5]}$.

We didn't encounter a difference in the percentage of terminal villi between normal and PE. On the contrary, Sankar et al., (2013), Predoi et al., (2015) and Weel et al. (2016) reported that the density of the terminal villi was significantly higher in PE. This may be explained by the presence of a population of early onset $\mathrm{PE}$ in their study group ${ }^{[1,7,8]}$.

Similar to what reported in the literature by Mendilcioglu et al., (2011), Zhang et al. (2012), Cali et al., (2013), Shaker and Sadik (2013), Afroze et al., (2016) and Dagdelen et al., (2016), we have found significant increase in apoptotic activity in trophoblastic cells as highlighted by caspase $3^{[6,14-18]}$. This can suggest that whatever the time of onset of $\mathrm{PE}$ the pathogenetic mechanisms are nearly similar. Increased apoptosis may be due to molecular defects in cytotrophoblasts; namely, reduction in syncytin 1 gene expression. In addition, it is expression of oxidative stress triggered by placental hypoxia ${ }^{[5,19,20]}$.

Being a co-receptor for transforming growth factor beta (TGF) 1 and 3, endoglin (CD 105) is known to affect vascularity. Endoglin expression in tumors is known to promote angiogenesis. On the other hand, serum endoglin is well known for its antiangiogenic effect, being one of the causes of systemic endothelial dysfunction in $\mathrm{PE}^{[21]}$.

In the current study, we have found a significant difference in the expression of (CD 105) between PE and normal placenta with increased expression in PE both in cyto and syncytiotrophoblasts of villi but not in the endothelial cells of fetal blood vessels.

These results were similar to those reported by Jeyabalan et al., (2008), Fang et al.,(2010) and
Shchyogolev et al. (2012) $)^{[22-24]}$. On the contrary, Weel et al., (2016) reported no difference between early onset, late onset PE and control group ${ }^{[7]}$.

It has been suggested that endoglin (CD105) gene transcription is upregulated by hypoxia secondary to upregulation of hypoxia inducible factor (HIF)-1 $\alpha$ protein and TGF beta ${ }^{[25-27]}$.

The same factors may lead to upregulation of vascular endothelial growth factor-A (VEGF-A) to stimulate angiogenesis. This may help to restore fetal placental circulation ${ }^{[28]}$

On the other hand, Mano et al. 2011 reported that endoglin (CD105) decreases the invasive function of extravillous trophoblasts that may contribute to the shallow trophoblastic invasion underlying the development of $\mathrm{PE}^{[29]}$.

Whether it has a role in the pathogenesis of PE or it is a compensatory mechanism for placental hypoxia needs further declaration.

Despite the significant overexpression of endoglin (CD105) that is expected to be correlated with angiogenesis, in the present study we found MVD in $\mathrm{PE}$ to be comparable to control group. Similarly were the results reported by Li et al., (2015) $)^{[30]}$.

On the other hand, other investigators reported decreased microvessel counts in PE placentas ${ }^{[7,9,11,31,32]}$. These studies included population of early onset PE and reported poor fetal outcome with FGR and still birth.

Although the reduction in angiogenic factors (placental growth factor PIGF and VEGF) secondary to increased trophoblastic apoptosis was expected to be associated with a reduction in MVD, it seems that this reduction is compensated for by angiogenesis due to placental hypoxia. Whether this compensatory effect is related to endoglin (CD105) overexpression isn't clear and can be a matter for further research especially, we haven't seen the reaction for endoglin in the endothelial cells ${ }^{[7]}$.

The comparable figures in MVD between normal and PE placenta may explain why some cases of PE especially late onset ones may not be associated with FGR.

\section{CONCLUSION}

We concluded that placenta from late onset $\mathrm{PE}$ without FGR still different from the normal placenta. 
Whatever, the onset of PE pathogenesis may be similar? Absence of changes in MVD may explain good fetal outcome.

\section{CONFLICT OF INTEREST}

There are no conflict of interest.

\section{REFERENCES}

1. Predoi C, Grigoriu C, Vladescu R, Mihart A. Placental damages in preeclampsiafrom ultrasound images to histopathological findings. Journal of medicine and life. 2015;8 (Spec Issue):62.

2. Kovo M, Schreiber L, Ben-Haroush A, Gold E, Golan A, Bar J. The placental component in early-onset and late-onset preeclampsia in relation to fetal growth restriction. Prenatal diagnosis. 2012;32(7):632-7.

3. Van der Merwe J, Hall D, Wright C, Schubert P, Grove D. Are early and late preeclampsia distinct subclasses of the disease-what does the placenta reveal? Hypertension in pregnancy. 2010;29(4):457-67.

4. LuJ,ZhouW-H,RenL,ZhangY-Z.CXCR4,CXCR7, and CXCL12 are associated with trophoblastic cells apoptosis and linked to pathophysiology of severe preeclampsia. Experimental and molecular pathology. 2016;100(1):184-91.

5. Roland CS, Hu J, Ren C-E, Chen H, Li J, Varvoutis MS, et al. Morphological changes of placental syncytium and their implications for the pathogenesis of preeclampsia. Cellular and molecular life sciences. 2016;73(2):365-76.

6. Dagdelen M, Temur M, Yilmaz Ö, Altındag T, Uslu T, Özbay PÖ. Placental bed apoptosis is increased in pregnant women with pre-eclampsia versus normotensive pregnant women. Journal of Obstetrics and Gynaecology. 2016;36(8):974-9.

7. Weel IC, Baergen RN, Romão-Veiga M, Borges VT, Ribeiro VR, Witkin SS, et al. Association between placental lesions, cytokines and angiogenic factors in pregnant women with preeclampsia. PloS one. 2016;11(6):e0157584.

8. Sankar KD, Bhanu PS, Ramalingam K, Kiran S, Ramakrishna B. Histomorphological and morphometrical changes of placental terminal villi of normotensive and preeclamptic mothers. Anatomy \& cell biology. 2013;46(4):285-90.
9. Higgins LE, de Castro NR, Addo N, Wareing M, Greenwood SL, Jones RL, et al. Placental features of late-onset adverse pregnancy outcome. PloS one. $2015 ; 10(6): \mathrm{e} 0129117$.

10. Sankar KD, Bhanu PS, Kiran S, Ramakrishna B, Shanthi V. Vasculosyncytial membrane in relation to syncytial knots complicates the placenta in preeclampsia: a histomorphometrical study. Anatomy \& cell biology. 2012;45(2):86-91.

11. Ptacek I, Smith A, Garrod A, Bullough $\mathrm{S}$, Bradley $\mathrm{N}$, Batra $\mathrm{G}$, et al. Quantitative assessment of placental morphology may identify specific causes of stillbirth. BMC clinical pathology. 2016;16(1):1.

12. VINNARS MT, Nasiell J, Ghazi S, Westgren M, Papadogiannakis N. The severity of clinical manifestations in preeclampsia correlates with the amount of placental infarction. Acta obstetricia et gynecologica Scandinavica. 2011;90(1):19-25

13. Stark MW, Clark L, Craver RD. Histologic differences in placentas of preeclamptic/eclamptic gestations by birthweight, placental weight, and time of onset. Pediatric and Developmental Pathology. 2014;17(3):181-9.

14. Mendilcioglu I, Karaveli S, Erdogan G, Simsek M, Taskin O, Ozekinci M. Apoptosis and expression of Bcl-2, Bax, p53, caspase-3, and Fas, Fas ligand in placentas complicated by preeclampsia. Clinical and experimental Obstetrics \& Gynecology. 2011;38(1):38-42.

15. Zhang L, Jia L, Cui S, Shi Y, Chang A, Wang $\mathrm{P}$, et al. AP-2 $\alpha$-dependent regulation of $\mathrm{Bcl}-2 / \mathrm{Bax}$ expression affects apoptosis in the trophoblast. Journal of molecular histology. 2012;43(6):681-9.

16. Cali U, Cavkaytar S, Sirvan L, Danisman N. Placental apoptosis in preeclampsia, intrauterine growth retardation, and HELLP syndrome: an immunohistochemical study with caspase-3 and bcl-2. Clin Exp Obstet Gynecol. 2013;40(1):45-8.

17. Shaker O, Sadik N. Pathogenesis of preeclampsia: implications of apoptotic markers and oxidative stress. Human \& experimental toxicology. 2013;32(11):1170-8.

18. Afroze SH, Kalagiri RR, Reyes M, Zimmerman JD, Beeram MR, Drever $\mathrm{N}$, et al. Apoptotic and stress signaling markers are augmented in preeclamptic placenta and umbilical cord. BBA clinical. 2016;6:25-30. 
19. Zhuang X-W, Li J, C Brost B, Xia X-Y, Bin Chen $\mathrm{H}$, Wang $\mathrm{C}-\mathrm{X}$, et al. Decreased expression and altered methylation of syncytin-1 gene in human placentas associated with preeclampsia. Current pharmaceutical design. 2014;20(11):1796-802.

20. Gao Y, He Z, Wang Z, Luo Y, Sun H, Zhou $\mathrm{Y}$, et al. Increased expression and altered methylation of HERVWE1 in the human placentas of smaller fetuses from monozygotic, dichorionic, discordant twins. PLoS One. 2012;7(3):e33503.

21. Nassiri F, Cusimano MD, Scheithauer BW, Rotondo F, Fazio A, Yousef GM, et al. Endoglin (CD105): a review of its role in angiogenesis and tumor diagnosis, progression and therapy. Anticancer research. 2011;31(6):2283-90.

22. Jeyabalan A, McGonigal S, Gilmour C, Hubel C, Rajakumar A. Circulating and placental endoglin concentrations in pregnancies complicated by intrauterine growth restriction and preeclampsia. Placenta. 2008;29(6):555-63.

23. Fang $\mathrm{M}, \mathrm{He} \mathrm{Y}, \mathrm{Li} \mathrm{H}, \mathrm{Wu} \mathrm{M}$, Shi $\mathrm{X}$, Du $\mathrm{H}$. Alterations of serum and placental endoglin in pre-eclampsia. Journal of International Medical Research. 2010;38(1):43-51.

24. Shchyogolev A, Dubova E, Pavlova K, Lyapin V, Sukhikh G. Expression of antiangiogenic factors in the placental structures in preeclampsia. Bulletin of experimental biology and medicine. 2012;154(2):287.

25. Yinon Y, Nevo O, Xu J, Many A, Rolfo A, Todros $\mathrm{T}$, et al. Severe intrauterine growth restriction pregnancies have increased placental endoglin levels: hypoxic regulation via transforming growth factor-beta 3. The American journal of pathology. 2008;172(1):77-85.
26. Oujo B, Perez-Barriocanal F, Bernabeu C, M Lopez-Novoa J. Membrane and soluble forms of endoglin in preeclampsia. Current molecular medicine. 2013;13(8):1345-57.

27. Gu Y, Lewis DF, Wang Y. Placental productions and expressions of soluble endoglin, soluble fms-like tyrosine kinase receptor-1, and placental growth factor in normal and preeclamptic pregnancies. The Journal of Clinical Endocrinology and Metabolism. 2008;93(1):260-6.

28. Szentpéteri I, Rab A, Kornya L, Kovács P, Brubel R, Joó JG. Placental gene expression patterns of endoglin (CD105) in intrauterine growth restriction. The Journal of Maternal-Fetal \& Neonatal Medicine. 2014;27(4):350-4.

29. Mano Y, Kotani T, Shibata K, Matsumura H, Tsuda H, Sumigama S, et al. The loss of endoglin promotes the invasion of extravillous trophoblasts. Endocrinology. 2011;152(11):4386-94.

30. Li Y, Zhao Y-J, Zou Q-Y, Zhang K, Wu Y-M, Zhou C, et al. Preeclampsia does not alter vascular growth and expression of CD31 and vascular endothelial cadherin in human placentas. Journal of Histochemistry and Cytochemistry. 2015;63(1):22-31.

31. Uras N, Oguz S, Zergeroglu S, Akdag A, Polat B, Dizdar E, et al. CD31 and Factor VIII in angiogenesis of normal and pre-eclamptic human placentas. Journal of Obstetrics and Gynaecology. 2012;32(6):533-6.

32. Shchegolev A, Lyapin V, Tumanova U, Vodneva D, Shmakov R. Histological hanges in the placenta and vascularization of its villi in early-and late-onset preeclampsia. Arkhiv patologii. 2016;78(1):13-8. 